\title{
Reflexões sobre alienação parental em um projeto de mediação de conflitos
}

\author{
Reflections on parental alienation in a conflict mediation project \\ Reflexiones sobre alienación parental en un proyecto de mediación de conflictos \\ Ariele Faverzani da $\mathrm{Luz}^{1}$ \\ Denise Gelain ${ }^{2}$ \\ Luana Rocha de Lima ${ }^{3}$ \\ Faculdade Meridional (IMED)
}

\begin{abstract}
Resumo
A Mediação de Conflitos é um processo de caráter amigável, que visa a resolução de demandas familiares, sobretudo aquelas que envolvem a Síndrome de Alienação Parental, sendo o diálogo a principal ferramenta para sua execução. Assim, este estudo tem por objetivo refletir sobre a importância da Mediação de Conflitos na amenização e/ou eliminação da Alienação Parental nos casos atendidos no projeto Mediação de Conflitos da Faculdade IMED de Passo Fundo-RS, no ano de 2013. Trata-se de uma pesquisa qualitativa de cunho exploratório, no qual foram utilizados como instrumentos o Termo de Mediação de cada caso e entrevistas semi-estruturadas. A exploração e a análise dos dados coletados foram realizadas por meio do método de Análise de Conteúdo de Bardin. Ao final, foi possível verificar que a Mediação de Conflitos obteve resultados positivos nos casos de Síndrome de Alienação Parental, revelando-se como uma técnica eficiente ao garantir o bem-estar dos filhos.

Palavras-chave: Mediação de conflitos; Família; Alienação parental; Psicologia.
\end{abstract}

\begin{abstract}
The Conflict Mediation is a process of friendly character, aimed at the resolution of family demands, especially those involving Parental Alienation Syndrome, being dialogue the primary tool for this execution. Thus, this study aims to reflect on the importance of Conflict Mediation on smoothing and/or elimination of Parental Alienation in the cases assisted at the Conflict Mediation project of the IMED College of Passo Fundo-RS, in 2013. It is a qualitative research of exploratory nature, in which were used as instruments the Term of Mediation of each case and semi-structured interviews. The exploration and analysis of the data collected were performed by means of the method of Bardin's Analysis Content. In the end, it was possible to verify that the Conflict Mediation obtained positive results in cases of Parental Alienation Syndrome, revealing itself as an effective technique to ensure the welfare of children.

Key-words: Conflict mediation; Family; Parental alienation; Psychology.
\end{abstract}

\section{Resumen}

La Mediación de Conflictos es un proceso de carácter amistoso, encaminada a la resolución de las demandas familiares, especialmente las relacionadas con el síndrome de Alienación Parental, siendo el diálogo la principal herramienta para su ejecución. Por lo tanto, este estudio tiene como objetivo reflexionar sobre la importancia de la Mediación de Conflictos en disminuir o eliminar la Alienación Parental en los casos atendidos en el proyecto de Mediación de Conflictos de la Facultad IMED de Passo Fundo-RS, en el año de 2013. Es una investigación cualitativa de naturaleza exploratoria, en que fueron utilizadas como instrumentos el Término de la Mediación de cada caso y entrevistas semiestructuradas. La exploración y análisis de los datos recogidos fueron realizados mediante el método de Análisis de Contenido de Bardin. Al final, fue posible comprobar que la mediación de los conflictos ha obtenido resultados positivos en los casos de síndrome de Alienación Parental, lo que se revela como una técnica eficaz para garantizar el bienestar de los niños.

Palabras-clave: Mediación de conflictos; Familia; Alienación Parental, Psicología.

\section{Introdução}

A família é um elemento básico da sociedade, sendo formada por seres com ancestrais em comum ou por uma ligação de laços afetivos (Mota, T. S., Rocha \& Mota, G. B. C., 2011). De acordo com Farias (2004), a diversidade e a complexidade das alterações

Endereço1: Passo Fundo - RS - Telefone: (54) 33133739 / 96081150

Endereço2: Sarandi - RS - Telefone: (54) 99879784

Endereço3: Passo Fundo - RS - Telefone: (54) 99554103 sociais contemporâneas trouxeram a necessidade de se renovar os modelos de famílias até então existentes. Os matrimônios, separações, adoções, fertilizações, entre outros arranjos presentes nas famílias contemporâneas fizeram com que surgissem curiosidades a respeito de novos status familiares, novos tipos de relações, tanto afetivas quanto jurídicas. Assim, diante de tantas evoluções e mudanças fica dificultoso definir apenas um conceito sobre família, uma vez que podem existir variados tipos de configurações familiares, tornandose imprescindível apenas a existência do afeto em 
todas elas.

Dentre as transformações ocorridas no interior da família, evidencia-se a facilidade de realizar um divórcio nos dias de hoje. No divórcio (art. $226 \S 6^{\circ}$ da Constituição Federal de 1988), não existe mais a necessidade da família seguir constituída com a presença do pai e da mãe na criação do (a) filho (a), o que tende a acarretar, em alguns casos, consequências inesperadas, tais como a Síndrome da Alienação Parental (SAP). A ocorrência da SAP, geralmente se dá quando os genitores não conseguem dar conta de separar a conjugalidade do papel de pai e mãe, acabando por tornar os filhos membros e reféns de um conflito do qual não the pertencem (Barufi \& Araújo, 2012). A criança, comumente, passa a ser um objeto nas mãos do genitor alienador, sendo programada, sem qualquer justificativa, para odiar e perpetuar o clima de desmoralização contra o genitor-alvo (Trindade, 2008).

Há várias técnicas e procedimentos que são utilizados para evitar ou amenizar as práticas da SAP, destacando-se a Mediação, que conforme as palavras de Calmon (2007) é um tipo de intervenção onde uma terceira pessoa auxilia os membros que se envolvem em conflitos a atingir voluntariamente uma decisão aceitável, ocorrendo de maneira confidencial e com uma metodologia própria.

A Mediação possui a capacidade de diminuir ou até mesmo amenizar o estado conflituoso dos divorciados, bem como as questões relacionadas à Síndrome de Alienação Parental, trazendo, portanto, benefícios especialmente nas relações familiares (Santos \& Melo Júnior, 2011). Além disso, conforme menciona Guedes-Pinto (2005), a mediação familiar é flexível, pois os conflitos podem ser encaminhados considerando as especificidades de cada caso. Neste sentido, a mediação familiar serve como um processo de construção da maturidade, sendo que o seu resultado poderá ser mais efetivo na medida em que se alicerçar as habilidades sociais de compreender e enfrentar os conflitos. Para superar a síndrome, os pais devem possuir qualidade nas funções parentais, equilíbrio emocional, grandioso amor pelos filhos e um auxílio tanto de profissionais da área do Direito quanto de profissionais da área da Psicologia (Leiria, 2007).

Desta forma, esta pesquisa vinculada a um Trabalho de Conclusão de Curso (TCC) desenvolvido durante a Graduação em Psicologia, pretende compreender e investigar mais profundamente a Mediação, que se encontra em amplo crescimento, buscando pautála como um instrumento capaz de ser empregado no melhor manejo das questões relacionadas às práticas de SAP.

A interlocução do Direito com a Psicologia é uma fusão de extrema e satisfatória eficácia, pois um poderá servir de ancora para o outro através de suas técnicas e procedimentos, possibilitando alcançar resultados positivos nos conflitos que envolvem famílias. Para melhor compreensão do tema em questão, esse estudo tem como objetivo analisar como a Mediação de Conflitos pode amenizar e/ ou eliminar as práticas da SAP nos casos atendidos durante o ano de 2013 no Núcleo de Práticas Jurídicas (NUJUR) da Faculdade Meridional (IMED), situada na cidade de Passo Fundo, Rio Grande do Sul. A sua realização foi possível graças à adesão de 4 (quatro) genitores, que obtiveram auxílio no processo de Mediação de Conflitos e se disponibilizaram a relatar suas experiências. Ademais, trata-se de uma pesquisa qualitativa de cunho exploratório, no qual permite com que o pesquisador pense livremente sobre o tema em questão (Dantas \& Cavalcante, 2006), fundamentando-se no método de Análise de Conteúdo de Bardin para exploração dos dados obtidos.

\section{Revisão bibliográfica}

\subsection{A família}

Há décadas a família se constitui como uma instituição onde o ser humano aprende e se prepara para viver em sociedade. Ao mesmo tempo, é o terreno fecundo para fenômenos culturais, tais como as escolhas profissionais e afetivas, e para a vivência de problemas e sucessos, possibilitando com que o ser humano se diferencie dos demais seres vivos (Farias \& Rosenvald, 2010).

Na percepção de Gonçalves (2010), a família reúne todas as pessoas ligadas por vínculo consanguíneo, pela afinidade ou através de uma adoção, abrangendo os cônjuges e companheiros, parentes e afins. Em razão de sua importância, possui especial proteção do Estado (art. 226 da Constituição Federal de 1988), que garante os direitos de seus integrantes por compartilharem como principal ponto a afetividade, visto que se não houver afeto, não haverá nenhum tipo de auxílio ou proteção a essa família falida (Dias, 2007).

Nos primórdios, o genitor masculino era quem detinha o poder na família e comandava os passos de todos que dela faziam parte; os filhos e até mesmo a esposa seguiam rigorosamente as regras que eram ditadas pela figura masculina (Dias, 2007). Contudo, com o decorrer dos anos, as transformações na cultura e nos valores da sociedade exigiram a criação de Leis para o divórcio e o direito de igualdade para a mulher perante o homem, destacando-se a Lei do Divórcio $\mathrm{n}^{\circ}$ $6.515 / 77$ e a Lei $n^{\circ} 4.121 / 62$ que se refere ao Estatuto da Mulher Casada. A partir disso, "a estrutura familiar tradicional, com o pai como único provedor e a mãe como única responsável pelas tarefas domésticas e pelo cuidado com os filhos, está passando por um período de transição na cultura brasileira" (Dessen, 2010, p. 209).

As formulações reflexivas que são possíveis de 
serem realizadas frente a esta transição são inúmeras. Entre elas, ressalta-se que a família atual não é melhor nem pior do que a família do passado, mas certamente é muito diferente dos modelos de famílias, das estruturas de poder e de afeto que habitaram, construíram e modelaram os arquétipos anteriores a este que hoje perduram (Souza, 2007).

Seguindo essa linha de pensamento, reforça-se que se a Constituição Federal abandonou o casamento como único tipo de família juridicamente tutelada, é porque abdicou dos valores que justificavam a norma de exclusão, passando a privilegiar a afetividade como necessária para realização pessoal de seus integrantes (Lôbo, 2002).

Pereira (2006, p. 180) assegura que "de fato, uma família não deve estar sustentada em razões de dependência econômica mútua, mas exclusivamente, por se constituir um núcleo afetivo, que se justifica, principalmente, pela solidariedade mútua". Assim, a composição de uma família deve se pautar unicamente pela presença do afeto entre seus membros, independentemente de sua configuração familiar.

Por conseguinte, a família se apresenta como uma instituição frágil, uma vez que se encontra em um constante processo de adaptação. Logo, estudála envolve, necessariamente, também estudar os processos de comunicação e as interações e relações existentes entre os seus membros, levando em consideração as tarefas de desenvolvimento individuais e grupais (Dessen, 2010).

\subsection{A Síndrome de Alienação Parental (SAP)}

A terminologia Síndrome de Alienação Parental apareceu pela primeira vez no artigo Recent Trends in Divorce and Custody Litigation, do psiquiatra americano Richard Gardner, em 1985. Segundo o autor da terminologia, a Síndrome de Alienação Parental apresenta-se como um distúrbio da infância que surge quase exclusivamente no contexto de disputas de custódia de crianças e se manifesta através de uma campanha denegritória realizada por um dos genitores contra o outro, fazendo na criança uma espécie de "lavagem cerebral" (Gardner, 2002). No Brasil, a SAP aparece com frequência em famílias que buscam o judiciário para resolver questões de divórcio e disputa de guarda dos filhos.

Em 26 de agosto de 2010 foi criada a Lei n ${ }^{\circ} 12.318$, que dispõe sobre a alienação parental. A referida Lei, considerou a prática como um ato parental que interfere na formação psicológica da criança ou do adolescente, sendo promovida ou induzida por um dos genitores, pelos avós ou por quem possui a sua guarda com o objetivo de prejudicar o genitor alienado. A principal vítima, no entanto, é a criança e/ou adolescente que, nos casos de divórcio, sofre com as sequelas que vêm acompanhadas da não elaboração adequada do luto conjugal e passa a ser um instrumento de agressividade nas mãos do genitor alienador (Dias, 2010).

Ressalta-se, ainda, a importância de saber diferenciar quando está ocorrendo a SAP e quando se trata realmente de uma situação mais grave envolvendo acusação de abuso sexual, pois as acusações vindas do alienador são tão insistentes que a criança pode acreditar ser verdadeiro tudo que lhe dizem, não conseguindo distinguir uma mentira. Por isso, diante das dificuldades em reconhecer a existência de fatos relacionados ao abuso sexual, os operadores do Direito e os profissionais de Psicologia devem ser cuidadosos e analisar ambos os lados, considerando se há outros tipos de sintomas que aparentam se tratar de um caso de SAP e se as acusações foram feitas em um momento de raiva e vingança de um dos genitores (Dias, 2010).

De todo o sofrimento que vem à mente quando se pensa em Alienação Parental, resta à certeza de que essa tão antiga e nociva prática deve ser cada vez mais alvo de um intenso repúdio da sociedade e da Justiça, visando um efetivo e sistemático combate até que seja extinta (Almeida, 2009). Igualmente, torna-se necessária a tomada de consciência de que esse tipo de abuso pode afetar significativamente a saúde emocional e o desenvolvimento sadio infantil, uma vez que a Síndrome de Alienação Parental é uma forma de abuso à integridade da criança que passa por uma adversidade de lealdade perante aos genitores (Dias, 2010).

\subsection{A Mediação de Conflitos e a Alienação Parental}

A Mediação é uma técnica extrajudicial na resolução de conflitos que tem como principal ferramenta o diálogo entre as partes com a colaboração de um mediador, visto que as partes podem não conseguir se comunicar de forma eficiente em razão da deterioração da relação entre ambas. Nesta situação, é recomendável que um terceiro auxilie as partes a alcançar uma posição mais favorável na situação controvertida por meio da Mediação (Tartuce, 2008).

A intercessão de uma terceira pessoa imparcial e neutra, sem nenhum poder de decisão, mostrase eficaz para auxiliar os envolvidos no conflito a alcançar voluntariamente um acordo aceitável para ambos. Barbosa (2003) corrobora ao salientar que o mediador não pode oferecer uma solução nem influenciar as partes durante a Mediação, pois a sua finalidade consiste em permitir com que os envolvidos possam difundir um diálogo, resgatando suas responsabilidades na resolução do problema em voga.

Assim, a Mediação demonstra estar em total concordância com o Direito de Família, na medida em que cria um ambiente de diálogo e permite com que os conflitos em questão possam ser atendidos amplamente, bem como alcancem resultados mais próximos à realidade enredada. Em relação às técnicas judiciais tradicionais, a Mediação apresenta 
vantagens significativas, como a celeridade, o menor custo e a confidencialidade. Os seus objetivos também são propícios para um acordo familiar, já que busca a identificação dos interesses, o equilíbrio entre as partes, a colaboração, a confiança e a estabilidade da relação entre pais e filhos (Santos \& Melo Júnior, 2011). Neste sentido, a prática da Mediação de conflitos se apresenta como um instrumento para o exercício pleno da cidadania, pois educa, facilita e produz mudanças, bem como permite a tomada de decisão pelos afetados por um conflito sem a influência de terceiros (Warat, 2000).

Com a Mediação os genitores têm a oportunidade de estabelecer seus papéis parentais e se voltar para o bem-estar dos filhos por meio da exposição dos afetos, da reorganização de suas identidades e da elaboração do luto do divórcio com a preservação do par parental (Silva, 2011). Por conseguinte, conforme apontam Santos e Melo Júnior (2011), assume-se uma postura a favor da prática da Mediação, não apenas para os casos de Síndrome de Alienação Parental (SAP), mas também para todo o contexto do Direito de Família.

\subsection{A Mediação de Conflitos e a interlocução com a Psicologia}

O Direito está repleto de componentes psicológicos, pois a maioria das questões jurídicas se encontra relacionada a problemas emocionais, o que justifica a interferência da Psicologia no propósito de obtenção da eficiência jurídica (Brito, 1999).

Em situações de conflitos, nota-se que o meio mais eficiente de intervir ou auxiliar no entendimento entre as partes, dá-se quando no processo de Mediação é permitida a verbalização dos sentimentos da parte comprometida, promovendo uma compreensão que ultrapassa a visão pessimista e de autopiedade pela situação que se apresenta (Braganholo, 2005).

Dessa forma, o trabalho do psicólogo consiste em atingir uma demanda relacionada à necessidade das pessoas de serem ouvidas além dos fatos, isto é, a importância de serem acolhidas sentimentalmente, visto que quando existe a procura de uma terceira pessoa na resolução de questões pessoais, significa que as pessoas em conflito não estão conseguindo encontrar uma solução para amenizar ou eliminar determinado impasse (Estrougo, 2002).

Entretanto, segundo Marodin e Breitman (2002), nem sempre os profissionais que trabalham com os procedimentos tradicionais estão capacitados a tratar de questões que envolvem afetividade e a observar situações encobertas, bem como dar-se conta dos verdadeiros motivos da procura pelo Judiciário. Portanto, a Mediação de Conflitos familiares é uma alternativa que vem para realizar uma modificação de paradigma através da promoção da capacidade de olhar para o outro e da busca jurídica de restauração pessoal (Braganholo, 2005). De acordo com Barbosa (2006, p. 7), “a definição de Mediação também se enquadra como espaço de criatividade pessoal e social, um acesso à cidadania. A Mediação encontra-se num plano que aproxima, sem confundir, e distingue, sem separar".

Progressivamente, a participação da Psicologia no terreno do Direito de Família, principalmente no que se refere à redução do sofrimento relacionado aos processos litigiosos, tem auxiliado os atores jurídicos a defrontar as situações legais envolvidas em questões conflituosas de maneira consciente e assertiva (Berlim \& Demutti, 2011).

\section{Método}

Trata-se de uma pesquisa qualitativa de cunho exploratório, vinculada a um Trabalho de Conclusão de Curso (TCC) de Graduação em Psicologia, que se realizou no Núcleo de Práticas Jurídicas (NUJUR) da Faculdade Meridional (IMED), localizada no município de Passo Fundo, no Estado do Rio Grande do Sul. O projeto foi aprovado pelo Comitê de Ética em Pesquisa (CEP) da referida instituição de ensino sob o número 348.263.

\subsection{Participantes}

Foram sujeitos desse estudo, 4 (quatro) genitores, sendo dois homens e duas mulheres, que participaram do processo de Mediação de Conflitos no Núcleo de Práticas Jurídicas (NUJUR) da Faculdade Meridional (IMED) de Passo Fundo, Rio Grande do Sul, durante o ano de 2013, que suscitaram a Síndrome de Alienação Parental. Nas quatro entrevistas coletadas, os participantes foram identificados como genitora R., genitor D., genitora T. e genitor N.

\subsection{Instrumentos}

Nesta pesquisa foram utilizados como instrumentos a observação participante; a análise de documentos, que envolveu o Termo de Mediação de cada caso, sendo este um relato fidedigno da Mediação realizada pelo NUJUR e assinado pelos mediandos e mediadores; e, a entrevista semiestruturada, na qual os participantes, após passado um período de tempo da Mediação, foram contatados para retornar ao NUJUR no intuito de verificar se houve a manutenção do acordo quanto aos comprometimentos firmados anteriormente na Mediação, bem como para constatar se a técnica foi efetiva na eliminação e/ou amenização da Síndrome de Alienação Parental (SAP).

$\mathrm{Na}$ mesma data em que foi realizada a entrevista semiestruturada, os genitores foram convidados para participar de forma voluntária da presente pesquisa, sendo entregue o Termo de Consentimento Livre e Esclarecido (TCLE).

Posteriormente, esclareceu-se que em nenhum momento haverá a identificação dos participantes a fim de garantir o sigilo e a privacidade das informações. Ainda, foi comunicado que, se no decorrer da pesquisa 
optassem por não mais participar, poderiam retirar seus consentimentos sem qualquer prejuízo e que não haveria benefício direto pela participação, mas que estariam contribuindo para uma maior compreensão sobre a questão da Alienação Parental e da Psicologia no processo de Mediação de Conflitos.

\subsection{Procedimento}

A coleta de dados ocorreu entre os meses de setembro e outubro de 2013, após a aprovação do Comitê de Ética em Pesquisa (CEP) da Faculdade Meridional (IMED), conforme o Parecer Consubstanciado $\mathrm{n}^{\circ}$ 348.263. A coleta de dados com os genitores que firmaram acordo com o projeto de Mediação de Conflitos aconteceu no Núcleo de Práticas Jurídicas (NUJUR) da referida instituição de ensino. As entrevistas, que foram gravadas e transcritas fielmente, buscaram obter informações sobre a efetivação dos acordos firmados na Mediação de Conflitos, procurando, dessa forma, saber se houve a amenização e/ou a solução do conflito que suscitou a demanda para a Mediação. Observa-se que antes de dar início à entrevista semiestruturada, ocorreu à leitura para cada genitor do Termo de Mediação, no qual constam as combinações realizadas no dia em que foi realizada a Mediação.

\subsection{Análise dos dados}

Para a análise dos dados coletados dos genitores que aderiram participar da pesquisa, foi utilizado o método de Análise de Conteúdo de Bardin. De acordo com Bardin (2009), é aplicado um conjunto de técnicas metodológicas aos dados com a finalidade de torná-los aptos a análise. Para a sua execução, é necessária a superação de três etapas, sendo elas: a pré-análise, a exploração do material e o tratamento dos resultados.

$\mathrm{Na}$ fase da pré-análise ocorre à organização, que tem por objetivo tornar operacionais as ideias, e a leitura flutuante dos documentos que serão estudados. Na fase da exploração do material, os dados começam a ser sistematizados e categorizados. No tratamento dos resultados, ocorre a análise e a interpretação dos dados obtidos em concomitância ao suporte teórico escolhido (Bardin, 2009).

\subsection{Resultados e discussão}

Após a realização das três etapas sugeridas pelo método de Análise de Bardin, as falas dos participantes foram agrupadas em três categorias de acordo com os objetivos da presente pesquisa, apresentadas a seguir:

1. Atuação da Psicologia no projeto de Mediação de Conflitos da Faculdade Meridional (IMED) de Passo Fundo-RS, em especial nos casos de Alienação Parental;

2. Sentimentos e expectativas dos genitores para com a participação no projeto Mediação de Conflitos;

3. O processo de Mediação de Conflitos e sua influência na amenização das práticas de Síndrome de Alienação Parental (SAP): as medidas tomadas pelos genitores após a realização da mediação.

\subsubsection{Atuação da Psicologia no projeto de Mediação de Conflitos da Faculdade Meridional (IMED) de Passo Fundo-RS, em especial nos casos de Alienação Parental}

APsicologia desenvolveu um trabalho significativo nesse ano vigente nos casos atendidos no Projeto Mediação de Conflitos da Faculdade Meridional (IMED) de Passo Fundo-RS, principalmente naqueles que demonstraram a prática da SAP, disponibilizando auxílio quando necessário e mantendo a neutralidade diante dos indivíduos que procuraram a Mediação.

As falas obtidas durante as entrevistas apontam a apreciação dos genitores sobre a participação da Psicologia na Mediação, bem como a importância dos encaminhamentos realizados pelas mediadoras, na época estagiárias de Psicologia, quanto à necessidade de tratamento psicológico aos filhos:

Eu achei que com as psicólogas ajudando na mediação foi muito bom, pois a minha filha já fazia acompanhamento psicológico antes da Mediação e ela ainda continua porque eu acho que o trabalho de vocês é muito bom e ajuda muito em conflitos tipo o meu, da questão da separação e a ausência do pai da V., lá ela pode entender certas coisas que as vezes era difícil de eu explicar (genitora R.).

Depois da Mediação eu procurei ajuda psicológica, pois eu já tinha feito essas consultas uma vez e me ajudava muito. Agora voltei de novo e percebo que fazendo as consultas eu consegui mudar algumas coisas e tenho mais contato com minha filha, conforme as falas do pessoal que participou da Mediação eu percebi que era muito importante a minha presença perto da V. (genitor D.).

A partir das falas dos participantes, foi possível constatar que a mediação combinada juntamente com o acompanhamento psicológico se revela como uma alternativa eficaz em casos de divórcios, uma vez que nenhuma criança e/ou adolescente passa ileso ao vivenciar uma mudança familiar tão significativa.

Wagner, Falcke e Meza (1997, p. 157) explicam que "as consequências do divórcio nos filhos estão diminuindo à medida que este está se tornando, a cada dia, mais comum e aceitável". Contudo, Giddens (1999) reconhece que os efeitos do divórcio na vida dos filhos serão sempre de difícil avaliação, porque jamais se terá conhecimento do que teria acontecido se os pais tivessem se mantido juntos. Neste sentido, vê-se a importância da abertura para o dialogo sobre este assunto com os filhos, visando proporcionar um maior entendimento e esclarecimento (Brito, 2007).

Ainda, foi possível verificar, nos casos atendidos, a importância da participação da Psicologia no terreno 
do Direito de Família, visto que permite à redução do sofrimento relacionada aos processos litigiosos e auxilia os atores jurídicos a defrontar as situações legais envolvidas de maneira consciente e assertiva (Berlim \& Demutti, 2011).

\subsubsection{Sentimentos e expectativas dos genitores para com a participação no projeto Mediação de Conflitos}

$\mathrm{Na}$ análise desta categoria foi possível, através da coleta de dados, conhecer os sentimentos e as expectativas dos genitores para com a intervenção/ processo de Mediação de Conflitos.

Assim, a citação abaixo extraída de uma entrevista evidencia:

Surgiu bastante efeito a conversa de nós dois aqui sem muitas brigas (...), foi um começo pra eu e o pai dela parar de brigar e pensar nela, agora ela até visita com frequência o pai, até almoçou no dia dos pais com ele (genitora R.).

Embora também tenha sido aludido pelos genitores que a convivência dos filhos com apenas um dos pais acarretou na diminuição do contato com o outro, identificou-se que a Mediação não gerou expectativas excessivas em relação aos filhos, uma vez que as exigências ficaram basicamente em torno do acordo firmado no NUJUR. Assim, sobre as expectativas com relação à Mediação, os sujeitos entrevistados expressaram que "a Mediação abriu portas para uma conversa depois, foi importante" (genitor D.).

Na Mediação, há a possibilidade de diminuir ou até mesmo eliminar o estado combatente dos divorciados e, consequentemente, de interferir diretamente na questão da Síndrome de Alienação Parental (SAP), pois, como já mencionado anteriormente, as situações alienadoras acontecem, principalmente, no decorrer do divórcio e na disputa de guarda dos filhos. Os genitores ao passarem pela Mediação, através da instauração do diálogo e da realização de acordos, irão enfrentar o fim do matrimônio de forma mais saudável, sem por em risco a convivência dos filhos com um de seus pais (Santos \& Melo Júnior, 2011). Deste modo, a Mediação parece ser, conforme refere Lowenstein (2008), uma alternativa eficaz para reduzir a hostilidade que a Síndrome de Alienação Parental (SAP) provoca.

Ainda que, comumente, ex-casais permaneçam hostis entre si, não deixar transpor aos filhos esses atritos assegura a responsabilidade e a saúde psíquica de todos os envolvidos. No caso dos genitores R. e D., houve a tentativa e a possibilidade de diálogo após a Mediação em prol da filha, demonstrando que mesmo em meio as suas diferenças e conflitos tiveram, enquanto genitores, a maturidade de separar os seus conteúdos divergentes e usar da conversação para não causar prejuízos a criança.
Frente a isso, vislumbra-se a importância de, cada vez mais, ser indicada a Mediação para pendências familiares, na medida em que esta oportuniza aos genitores estabelecer os seus papéis parentais, preocupar-se com o bem-estar dos filhos e elaborar o luto do divórcio conjugal (Silva, 2011).

3.5.3 O processo de Mediação de Conflitos e sua influência na amenização das práticas de Síndrome de Alienação Parental (SAP): as medidas tomadas pelos genitores após a realização da mediação

As principais medidas tomadas, após a realização da Mediação, relatadas pelos genitores entrevistados nesta pesquisa, referem-se a um comprometimento ativo com a educação dos filhos, participação constante no cotidiano dos mesmos e convivência mais saudável com o genitor que não possui a guarda, como verificado nas falas a seguir:

A gente conversa por telefone (...). Ele tá indo nas reuniões do colégio (...), a diretora do colégio pediu, vocês vão ter que encaminhar ela para um psicólogo, porque ela tá muito atrasada nos estudos e ela não consegue distinguir a figura do pai. A figura do pai, ela dizia que o pai era o avô, até pra ela agora tá sendo bom, porque agora ela sabe que tem o pai dela, tem o vô (genitora R.).

Acho que ela precisava ficar um pouco com o pai, não sei, enfim tá tudo bem, pelo menos quando ela vem ficar uns dias na minha casa é muito bom, a gente se diverte muito e ela está mudando, me obedece mais (genitora T.).

Neste sentido, através da análise das falas da amostra desta pesquisa, constatou-se que a Mediação obteve êxito, pois alcançou o seu objetivo de ajudar as partes a agir em busca de um acordo, além de permitir que um passasse a olhar para o outro não como um rival a ser vencido, mas como alguém que também está procurando uma melhor maneira de resolver os conflitos (Chaves \& Maciel, 2005).

Por meio dessa perspectiva é que surge, segundo Braganholo (2005, p. 76-77), “a proposta de uma Mediação transformadora, capaz de desenvolver habilidades necessárias para o ser humano lidar com seus conflitos internos e externos". Este demonstra ser um caminho seguro e inovador para recuperar a sensibilidade pouco exercida no Direito de Família.

\section{Considerações finais}

A partir da realização desta pesquisa, ficou ainda mais explícito o sofrimento que a Síndrome de Alienação Parental (SAP) pode causar aos envolvidos, principalmente a criança e/ou adolescente, sendo capaz de chegar ao ponto de interromper laços paternos ou maternos e de causar a perda da esperança de reatar esse convívio novamente. 
A Mediação de Conflitos se revela como uma ferramenta eficiente para resolução de questões familiares, bem como para sanar parte dos impasses presentes no âmbito jurídico ao apresentar três pilares significativos: a celeridade, o menor custo e a confidencialidade. Soma-se a esse processo, ainda, a intercessão de uma terceira pessoa imparcial e neutra, que tem como função apenas auxiliar os envolvidos no conflito a alcançar voluntariamente uma decisão aceitável em comum acordo.

Assim, verificou-se que a utilização da Mediação nos casos de Síndrome de Alienação Parental (SAP) promove tanto a amenização quanto a eliminação de sua prática, uma vez que agrega as contribuições da Psicologia com os aportes do Direito, o que proporciona uma abrangência do conflito familiar em sua totalidade. Sabe-se que a maioria dos conflitos familiares possui uma carga emocional significativa e que, por vezes, a raiz do problema está relacionada à qualidade das relações afetivas e não unicamente às questões mais burocráticas, evidenciando a importância da aplicabilidade da Mediação.

A Psicologia, no propósito de obtenção da eficiência jurídica, tem auxiliado as partes a defrontar as situações legais de maneira consciente e assertiva através do diálogo, possibilitando aos indivíduos as condições necessárias para expressar seus sentimentos não elaborados de uma forma mais adequada, assim como explorar a escuta como meio complementar a resolução de conflito.

Deste modo, através deste estudo, pode-se refletir sobre a crescente e visível presença da Síndrome de Alienação Parental (SAP) nos últimos tempos nos casos de divórcio e disputa de guarda dos filhos. De tal modo, foi constatado que a procura pela Mediação é um caminho eficiente para a resolução dos casos de SAP, na medida em que muitas vezes o diálogo proposto e construído por ela pode evitar com que sejam agravados os conflitos. Além disso, a Mediação possibilita fortalecer os vínculos familiares através da interrupção de atitudes que culminam no cometimento da Alienação Parental, responsável por colocar em risco a saúde mental e emocional dos filhos que são as principais vítimas das manipulações e, portanto, vulneráveis às desavenças de seus genitores.

\section{Referências}

Almeida, M. G. (2009). A síndrome da alienação e da morte parental: breves considerações. Revista Erga Omnes, (5), 48-53.

Barbosa, A. A. (2003). Mediação Familiar: uma vivência interdisciplinar. In: G. C. Groeninga, \& R. C. Pereira (Coords.), Direito de Família e Psicanálise (p. 339-346). Rio de Janeiro: Imago.

Barbosa, A. A. Relação de Respeito. (2006). Boletim Instituto Brasileiro de Direito de Família, 6 (38), 7.

Bardin, L. (2009). Análise de conteúdo. Lisboa: Edições 70.

Barufi, M. T., \& Araújo, S. M. B. (2012). Cartilha Alienação Parental: vidas em preto e branco. Porto Alegre: OAB/RS.
Berlim, C. S., \& Demutti, R. (2011). Reflexões sobre as possibilidades de intervenção em Psicologia Jurídica. In: Associação Brasileira de Psicologia Jurídica (Org.), Anais do I Congresso Brasileiro e II Simpósio Sul-Brasileiro de Psicologia Jurídica. Porto Alegre: ABPJ.

Braganholo, B. H. (2005). Novo Desafio do Direito de Família Contemporâneo: a mediação familiar. Revista CEJ, (29), 70-79.

Brasil. (1988, Outubro 5). Constituição Federal de 1988, capítulo VII: da família, da criança, do adolescente, do jovem e do idoso. Acessado de http://www.planalto.gov.br/ccivil_03/ constituicao/constituicao.htm.

Brasil. (1962, Agosto 27). Lei $n^{\circ} 4.121$, de 27 de agosto de 1962: dispõe sobre a situação jurídica da mulher casada. Acessado de http://www.planalto.gov.br/ccivil_03/leis/1950-1969/L4121. htm.

Brasil. (1977, Dezembro 26). Lei n ${ }^{\circ} 6.515$, de 26 de dezembro de 1977: regula os casos de dissolução da sociedade conjugal e do casamento. Acessado de http://www.planalto.gov.br/ccivil_03/leis/ 16515.htm.

Brasil. (2010, Agosto 26). Lei n ${ }^{\circ} 12.318$, de 26 de agosto de 2010: dispõe sobre a alienação parental. Acessado de http://www. planalto.gov.br/ccivil_03/_Ato2007-2010/2010/Lei/L12318.htm.

Brito, L. M. T. (1999). De competências e convivências: caminhos da Psicologia junto ao Direto de Família. In: L. M. T. Brito (Org.), Temais de Psicologia Jurídica (p. 171-186). Rio de Janeiro: Relume-Dumará.

Brito, L. M. T. (2007). Família pós-divórcio: a visão dos filhos. Psicol. cienc. prof., 27 (1), 32-45.

Calmon, P. (2007). Fundamentos da Mediação e da Conciliação, ( $1^{\mathrm{a}}$ ed.). Rio de Janeiro: Forense.

Chaves, N. M., \& Maciel, S. K. (2005). Mediação familiar nos casos de dissolução de sociedade e vínculo conjugal. In: R. M. Cruz, S. K. Maciel, \& D. C. Ramirez (Orgs.), O trabalho do psicólogo no campo jurídico (p. 171-190). São Paulo: Casa do Psicólogo.

Dantas, M., \& Cavalcante, V. (2006, Abril 18). Pesquisa Qualitativa e Pesquisa Quantitativa. Acessado de http://pt.scribd. com/doc/14344653/Pesquisa-qualitativa-e-quantitativa.

Dessen, M.A. (2010). Estudando a família em desenvolvimento: desafios conceituais e teóricos. Psicol. cienc. prof., 30, 202-219.

Dias, M. B. (2010). Alienação Parental e suas consequências. Acessado de http://www.mariaberenice.com.br/uploads/ aliena\%E7\%E3o_parental_e_suas_consequencias.pdf.

Dias, M. B. (2007). Manual de Direito das Famílias, (4 ed.). São Paulo: Revista dos

Tribunais.

Estrougo, M. G. (2002). Direito de Família: quando a família vai ao tribunal. In: D. Zimerman, D., \& A. C. M. Coltro (Orgs.), Aspectos psicológicos na prática jurídica (p. 203-215). Campinas: Millennium.

Farias, C.C. (2004). Direito à Família. Revista Eletrônica Mensal do Centro de Pesquisas Jurídicas - UNIFACS, (46), 1-17.

Farias, C. C., \& Rosenvald, N. (2010). Direito das Famílias, $\left(2^{\mathrm{a}}\right.$ ed.). Rio de Janeiro: Lumen Juris.

Gardner, R. (2002). O DSM-IV tem equivalente para o diagnóstico de Síndrome de Alienação Parental (SAP)?. Acessado de http://www.alienacaoparental.com.br/textos-sobre-sap-1/o-dsmiv-tem-equivalente.

Giddens, A. (1999). A Terceira Via: reflexões sobre o impasse político atual e o futuro da social-democracia. Rio de Janeiro: Record.

Gonçalves, C. R. (2010). Direito Civil Brasileiro, (7 ed.). São Paulo: Saraiva.

Guedes-Pinto, A. C. R. (2005). Aspectos sociais da Mediação Familiar. In: Associação de Pais e Mães Separados (Org.), Mediação Familiar (p. 27-41). Porto Alegre: Equilíbrio.

Leiria, C. S. (2007, Março 27). Síndrome da Alienação Parental. Acessado de http://www.pontojuridico.com/modules.php ?name $=$ News \&file $=$ article $\&$ sid $=151$.

Lôbo, P. L. N. (2005, Setembro 3). Entidades Familiares Constitucionalizadas: para além do numerus clausus. Acessado de http://mundojuridico.adv.br/sis_artigos/artigos.asp?codigo=264. 
Lowenstein, L. (2008). O que pode ser feito para diminuir a implacável hostilidade que leva à Síndrome de Alienação Parental? . Acessado de http://www.alienacaoparental.com.br/textos-sobresap-1/lowenstein-2008.

Marodin, M., \& Breitman, S. (2002). A prática da moderna mediação: integração entre a psicologia e o direito. In: D. Zimerman, \& A. C. M. Coltro (Orgs.), Aspectos psicológicos na prática jurídica (p. 471-488). Campinas: Millennium.

Mota, T. S., Rocha, R. F., \& Mota, G. B. C. (2011, Janeiro 15). Família - Considerações gerais e historicidade no âmbito jurídico. Acessado de http://www.ambitojuridico.com.br/site/index.php?n_ link=revista_artigos_leitura\&artigo_id $=8845$.

Pereira, R. C. (2006). Princípios fundamentais norteadores do direito de família. Belo Horizonte: Del Rey.

Santos, R. S., \& Melo Júnior, R. F. (2011). Síndrome de Alienação Parental e Mediação Familiar - Do conflito ao diálogo. Revista do Curso de Direito - UNIFACS, (128), 1-24.

Silva, D. M. P. (2011, Dezembro 19). Mediação familiar em casos de alienação parental. Acessado de http://www. ambito-juridico.com.br/site/index.php?n_link=revista_artigos_ leitura\&artigo id $=10856$.

Souza, I. M. C. C. (2007). Direito de Família, diversidade e multidisciplinaridade. Porto Alegre: Instituto Brasileiro de Direito de Família-RS. Método.

Tartuce, F. (2008). Mediação nos Conflitos Civis. São Paulo:

Trindade, J. (2008). Síndrome de Alienação Parental (SAP). In: M. B. Dias (Org.), Incesto e Alienação Parental: realidades que a Justiça insiste em não ver (p. 101-111). São Paulo: Editora Revista dos Tribunais.

Wagner, A., Falcke, D., \& Meza, E. (1997). Crenças e Valores dos Adolescentes acerca de Família, Casamento, Separação e Projetos de Vida. Psicologia: Reflexão e Crítica, 10 (1), 155-167.

Warat, L. A. (2000). Mediación el derecho fuera de las normas: para una teoría no normativa del conflicto. Scientia Iuris, (4), 09.

\author{
Recebido: 04/01/2014 \\ Última revisão: 25/07/2014 \\ Aceite final: 23/08/2014
}

Sobre os autores:

Ariele Faverzani da Luz - Graduanda do $9^{\circ}$ semestre do curso de Psicologia da Faculdade Meridional (IMED) Telefone: (54) 33133739 / 96081150

E-mail: arielefl@outlook.com

Denise Gelain - Titulação Acadêmica: Mestre em Educação pela Universidade de Passo Fundo (UPF), especializações em Intervenções Psicossociais e Arteterapia, graduação em Psicologia pela Universidade de Passo Fundo (UPF). Telefone: (54) 99879784

E-mail: denigelain@terra.com.br

Luana Rocha de Lima - Graduação em Psicologia pela Faculdade Meridional (IMED)

Telefone: (54) 99554103

E-mail: luanarochal@hotmail.com 